\title{
TRANSPLANTE HEPÁTICO SEM TRANSFUSÃO SANGUÍNEA
}

\section{LIVER TRANSPLANTATION WITHOUT BLOOD TRANSFUSION}

\author{
João Eduardo Leal Nicoluzzi, TCBC-PR ${ }^{1}$; Marlus Moreira ${ }^{2}$; Pedro Ernesto Caron, TCBC-PR ${ }^{3}$
}

\section{INTRODUÇÃO}

A partir da década de 90 começaram a surgir na literatura relatos de transplantes hepáticos ortotópicos sem uso de transfusão sangüínea ou hemoderivados, normalmente relacionados a fatores religiosos envolvendo pacientes Testemunhas de Jeová1.

Este procedimento passou a ser possível somente após refinamento cirúrgico e anestésico, e avanços na medicina intensiva, com diminuição da morbidade e mortalidade. Contudo, uma cirurgia desse porte, sem uso de hemoderivados permanece como um desafio para as equipes cirúrgicas e anestésicas ${ }^{1}$.

Procedimentos de transplantes hepáticos sem uso de hemoderivados em pacientes sem motivos religiosos permanecem raros. O objetivo deste estudo é relatar dois casos de transplante de fígado sem transfusão de sangue, sem razão religiosa, assim como a evolução pós-operatória desses pacientes.

\section{RELATO DOS CASOS}

Ambos os pacientes eram do sexo masculino, com idades de 44 e 41 anos. Os tipos sanguiíneos eram AB negativos e portadores de cirrose hepática alcoólica.

Pré-operatoriamente foram listados de acordo com a classificação de Child-Pugh sendo o caso 1 com índice B7 e o caso 2 com índice B8.

O paciente 1 apresentava hemoglobina de $16 \mathrm{mg} / \mathrm{dl}$, volume globular de $45 \%$ e contagem de plaquetas de 80.000/11. Os demais exames não revelaram alterações no sistema hematopoiético.

O paciente 2 apresentava hemoglobina de $17,1 \mathrm{mg} /$ dl, volume globular de $48 \%$ e contagem de plaquetas de 196.000/11. Nenhuma alteração foi encontrada em relação à hematopoiese.

Em nenhum momento foi utilizada qualquer medicação para estimulação da eritropoiese.

Os atos cirúrgicos foram executados conforme a técnica clássica para transplante hepático ortotópico. A drenagem biliar foi feita em ambos os casos com derivação bíliodigestiva em Y de Roux. A temperatura corporal foi aferida com termômetro intra-traqueal e variou entre 35,5 e $36,5^{\circ} \mathrm{C}$, mantida com auxílio de cobertor térmico em sala aquecida para evitar hipotermia com conseqüente coagulopatia. Utilizou-se equipamento para recuperação de hemácias intra-operatória, bem como bisturi de argônio para coagular qualquer superfície cruenta. As anastomoses foram feitas em espaço restrito, o que evitou superfícies cruentas alargadas com maior probabilidade de sangramentos. Foram utilizados drenos de Jackson Pratt para monitorar sangramentos pós-operatórios. A imunossupressão foi induzida intra-operatoriamente com metilpredinisolona na dose de 500mg.

No caso 1 a perda sangüínea estimada foi de $190 \mathrm{ml}$, volume recuperado sob forma de concentrado de hemácias pelo equipamento para recuperação de hemácias intra-operatória, após filtragem per-operatória de $2.100 \mathrm{ml}$. No caso 2 a perda sangüínea estimada foi de $180 \mathrm{ml}$ após filtragem peroperatória de $1.980 \mathrm{ml}$.

Esses volumes foram desprezados em ambos os casos. Ao tempo de fechamento da pele o paciente 1 apresentava hematócrito de $48 \%$ e diurese de $50 \mathrm{ml} /$ hora. No paciente 2 o hematócrito foi de $45 \%$ com diurese de $40 \mathrm{ml} / \mathrm{hora}$.

Os pacientes foram transferidos para unidade de terapia intensiva procedendo-se a sangrias para adequar o volume globular em ambos os pacientes. No paciente 1 foi flebotomizado $500 \mathrm{ml}$ de sangue, reduzindo o volume globular de $48 \%$ para $38 \%$ no segundo dia após sangria. O paciente 2 sofreu sangria de $350 \mathrm{ml}$, o que reduziu o volume globular de $45 \%$ para $30 \%$ no segundo dia após sangria.

Os pacientes mantiveram-se estáveis entre os atos cirúrgicos e o pós-operatório imediato. No seguimento póstransplante os pacientes permaneceram sob cuidados intensivos por seis a 10 dias até a alta hospitalar nas condições conforme Tabela 1.

\section{DISCUSSÃO}

Com o aumento do conhecimento público em relação aos riscos das transfusões sangüíneas e de hemoderivados, a medicina vem adaptando-se com técnicas para incrementar a hematopoiese, evitar distúrbios de coagulação e diminuir a perda sangüínea intra-operatória. Recursos de suma importância em cirurgias de grande por-

1. Cirurgião Digestivo, Coordenador do Programa de Transplante Hepático e Pancreático do Hospital Angelina Caron (HAC); Mestre e Doutor em Cirurgia; Professor Adjunto da Pós-Graduação de Cirurgia da PUC-PR.

2. Residente do $2^{\circ}$ Ano de Cirurgia Geral do HAC.

3. Cirurgião-Geral, Chefe do Serviço de Cirurgia do HAC; Mestre em Cirurgia PUC-PR.

Recebido em 08/06/2004

Aceito para publicação em 07/12/2004

Trabalho realizado no Serviço de Cirurgia do HAC, Campina Grande do Sul, Paraná. 
Tabela 1 - Demonstrativo da Evolução Pós-Transplante Hepático sem Transfusão Sangüínea.

\begin{tabular}{lcccc}
\hline Avaliações Laboratoriais & \multicolumn{2}{c}{$\begin{array}{c}\text { Primeiro dia } \\
\text { Pós-transplante }\end{array}$} & \multicolumn{2}{c}{ Alta hospitalar } \\
& Paciente 1 & Paciente 2 & Paciente 1 & Paciente 2 \\
\hline Volume Globular(\%) & 48 & 45 & 38 & 30 \\
Hemoglobina (mg/dl) & 17,1 & 15,7 & 14,9 & 9,8 \\
Plaquetas (fil) & 88.000 & 150.000 & 108.000 & 208.000 \\
RNI & 2,39 & 2,72 & 1,52 & 1,77 \\
Albumina (g/dl) & 2,80 & 2,60 & 3,40 & 3,30 \\
Bilirrubinas Totais (mg/dl) & 2,90 & 2,40 & 1,0 & 0,71 \\
FK 506 (ng/dl) & 8,0 & 7,40 & 8,5 & 7,60 \\
\hline
\end{tabular}

te, onde o uso de sangue é freqüente como observado nos transplantes hepáticos. Boa parte desses avanços é creditada à cirurgia cardíaca, contudo nem todos foram transferidos à cirurgia digestiva ou foram, mas não plenamente difundidos. É o que ocorre com os aparelhos de recuperação intra-operatória de hemácias, os quais tiveram seu uso restringido por receio de contaminação sistêmica por flora intestinal ou difusão de células tumorais, hoje desmentidos por estudos em cirurgia traumática com perfuração intestinal e em cirurgias neoplásicas, nessas associado ao uso de filtros especiais ${ }^{1}$.

Outro fator relevante para o desenvolvimento dessas técnicas é o aumento de pessoas com convicções religiosas que não aceitam sangue, como é o caso das Testemunhas de Jeová. O paciente para entrar no protocolo de transplante sem transfusão deve passar por alguns critérios de exclusão, os quais criados na Universidade de Pittsburgh ${ }^{1}$, vêm sendo adotados por muitos serviços ${ }^{1-3}$, são eles: (1) hematócrito < 35 mesmo após tratamento com eritropoietina; (2) contagem de plaquetas $<100.000 \times 10^{9} /$ L; (3) tempo de protrombina > 15 segundos; (4) conhecimento de anatomia venosa esplâncnica que requeira reconstrução vascular durante o transplante; (5) sangramento ativo; (6) insuficiência renal e disfunção de outro órgão importante exceto o fígado.

Pré-operatoriamente o uso de eritropoietina humana recombinante está cada vez mais comum em pacientes anêmicos a serem submetidos a cirurgias com potencial para perda sangüínea volumosa, sendo as melhores respostas obtidas nesse tipo de paciente ${ }^{1}$. No manejo pré-transplante deve ser feito 50 a $100 \mathrm{U} / \mathrm{Kg}$ subcutâneas três vezes por semana ${ }^{1-4} \mathrm{e}$ suplementação com sulfato ferroso via oral de $8 / 8$ horas diariamente ${ }^{1}$.

Espera-se aumento médio de oito pontos no hematócrito do paciente manejado dessa maneira por tempo mínimo de quatro semanas, sendo que aumentos significativos não foram observados em menos de duas semanas de tratamento ${ }^{1}$. Infelizmente tal abordagem não está livre de efeitos colaterais e atenção deve ser dada a possíveis elevações de pressão arterial e trombose de acessos venosos instalados permanentemente ${ }^{1}$.

No manejo intra-operatório está envolvido tempo de isquemia mínimo, com doadores locais apenas e com a sala mantida aquecida para evitar hipotermia com conseqüente coagulopatia ${ }^{2,5}$. Todas amostras sangüíneas também devem ser restritas a um mínimo possível durante o ato cirúrgico ${ }^{2}$. Monitor para tromboelastografia deve ser usado primariamente para se ter acesso ao status de coagulação do paciente ${ }^{2}$.

Plaquetoferese também é outro recurso preconizado, realizada após a indução anestésica, flebotomizando-se 5 a 7 litros de sangue num fluxo de 60 $\mathrm{ml} / \mathrm{min}$ em unidade de plaquetoferese. Isso resulta em bolsa de 250 a $300 \mathrm{ml}$ de concentrado de plaquetas com $3 \times 10^{9} / \mathrm{L}$ a $8 \times 10^{9} / \mathrm{L}$ de plaquetas, equivalente a 6 a $8 \mathrm{U}$ de plaquetas doadas ${ }^{2}$. O sangue pobre em plaquetas deve ser reinfundido lentamente para manter a capacidade de oxigenação tecidual e o plasma rico em plaquetas infundido após a reperfusão ${ }^{2}$. Hemodiluição isovolêmica é alcançada em conjunto com a plaquetoferese pela remoção de $2 \mathrm{U}$ (cada uma com cerca de $500 \mathrm{ml}$ ) de sangue total com estocagem em embalagem própria que capacite posterior reinfusão dos mesmos.

Quando a solução escolhida para manter a normovolemia for cristalóide cuidado especial deve ser tomado para não infundir mais que $15 \mathrm{ml} / \mathrm{Kg} / \mathrm{hora}$ de solução fisiológica $0,9 \%$, o que diluiria tampões extracelulares gerarando acidose hiperclorêmica. Por isso soluções colóides devem complementar o manejo, bem como albumina quando seu uso for permitido pelo paciente ${ }^{3}$.

No manejo pós-operatório monitorização com tromboelastograma, tempo de ativação da protrombina e contagem de plaquetas devem ser mantidos e qualquer fibrinólise pode ser corrigida com ácido $\in$-aminocapróico ${ }^{2}$. Suplementação com eritropoietina e sulfato ferroso também são mantidos até o paciente atingir hematócrito maior que $35 \%{ }^{2}$.

O estado fisiológico dos pacientes, com graduação Child-Pugh favorável, associado à técnica operatória cuidadosa e tecnologia avançada culminou com procedimento operatório satisfatório e sangramento mínimo. Desse modo, fica evidente a factibilidade de transplante hepático ortotópico sem infusão de sangue, seja em pacientes selecionados e preparados pré-operatoriamente ou em outros casos mediante técnica apurada. 
ABSTRACT

Orthotopic liver transplantation (OLT) usually requires large amounts of blood transfusion. Reports of OLT without transfusion are scarce and often associated to religious reasons. Herein we report two cases of OLT successfully managed without blood transfusion and not related to religious beliefs (Rev. Col. Bras. Cir. 2005; 32(4): 220-222).

Key words: Liver transplantation; Blood transfusion

\section{REFERÊNCIAS}

1. Baldry C, Backman SB, Metrakos P, et al. Liver transplantation in a Jehovah's Witness with ankylosing spondylitis. Can J Anesth. 2000; 47(7):642-6.

2. Ramos HC, Todo S, Kang Y, et al. Liver Transplantation without the use of blood products. Arch Surg. 1994;129(5):528-33

3. Seu P, Neelankanta G, Csete M, et al. Liver transplantation for fulminant hepatic failure in a Jehovah's Witness. Clin Transplant. 1996;10(5):404-7.

4. Goodnough LT, Monk TG, Andriole GL. Erythropoietin therapy. N Eng J Med. 1997; 336(13):933-8.
5. Lewis JH, Bontempo FA, Awad SA, et al. Liver Transplantation: intraoperative changes in coagulation factors in 100 first transplants. Hepatology. 1989;9(5):710-4.

Endereço para correspondência:

Dr. João Eduardo Leal Nicoluzzi

Rua Santo Amaro, 118.

Bairro Água Verde

80.620-330 - Curitiba - PR

E-mail: jenicoluzz@yahoo.com 